Mittheilung ans dem Königl. Entbindungsinstitut in Dresden.

\title{
Beitrag zum kyphotisch nicht rachitischen und zum kyphoskoliotisch-rachitischen Becken.
}

\author{
Von
}

A. Götze.

(Mit 11 Holzschniten und 3 Abbildungen auf Taf. III.)

Die Veränderungen, welche das rachitis che Becken durch Skoliose und Kyphose, resp. durch Kyphoskoliose erfährt, sind noch nicht genug untersucht und doch in praktischer Hinsicht von grossem Werthe. Um die Entstehung dieser Veränderungen $\mathrm{zu}$ verstehen, hat man sich zunächst des kyphotischen Beckens zu erinnern, wie es durch eine dorsale Kyphose aus einem ganz normalen Becken entwickelt wird.

Die Lehre vom kyphotisch-verengten Becken gehört erst der zweiten Hälfte dieses Jahrhunderts an, seitdem Breisky die Art und Entstehung dieser Beckendeformität richtig erkannte. Weitere werthvolle Untersuchungen über das kyphotische Becken sind von Moor, Höning, Fehling, Schilling u. a. angestellt. Sie alle beschreiben orwachsene Becken mit lumbosacraler resp. lumbodorsaler Kyphose. Ein kindliches Becken dagegen, an dem die deutlichen Veränderungen durch die Kyphose bereits zu sehen, resp. in den Anfängen und leisen Andeutungen zu beobachten sind, ist bisher noch nicht beschrieben worden. Ein solches Becken ist aber einerseits das Vorbild für ein erwachsenes kyphotisches Becken; andererseits wird der Vergleich mit einem rachitischen kindlichen Becken die prägnanten Unterschiede kennen lehren und zeigen, welche schroffen Gegensätze bereits zwischen einem kindlichen, rein rachitischen und einem kindlichen kyphotischen Becken bestehen. 
Ist dies erst festgestellt, dann versteht man ganz anders, wie ein ursprünglich rachitisches Becken durch eine spätere Skoliosis oder Kyphosis abgeändert wird, d. h. wie die rachitischen Zeichen dadurch etwas verwischt oder ausgeglichen werden, doch nur insoweit, dass sie immer noch unverkennbar sind.

Derartige, nämlich kyphotisch-rachitische und kyphoskoliotischrachitische Becken ${ }^{1}$ ) sind nur von wenigen eingehend beschrieben worden. Breisky und Litzmann erwähnen sie in ihren Werken mit kurzen, aber treffenden Worten. Erst in neuerer Zeit ist diese Beckenform zum Gegenstande eingehenderen Studiums gemacht worden von König, und hauptsächlich von Leopold. Letzterer hat in seinem Werke: „Das skoliotisch- und kyphotischrachitische Becken" auf Grund eigener Untersuchungen an Lebenden und an einer grossen Anzahl von Präparaten die Hauptmerkmale, sowie die Entstehung obiger Beckenabnormitäten erörtert und die Lehre vom s.-r, und k.-s.-r. Becken wesentlich erweitert und vervollständigt. Bei der Beschreibung des s.-r. Beckens geht L eopold von den Formveränderungen aus, welche ein kindlich rachitisches Becken durch eine Skoliosis erleidet, wobei sich zeigt, dass das kindlich s.-r. Becken ganz das Vorbild eines derartigen erwachsenen Beckens ist. Betreffs der Aetiologie kommt Verfasser zu der Ansicht, dass die Dislocation an der Wirbelsäule das primäre, die Veränderungen am Kreuzbeine verursachende Moment ist. Nachdem die Veränderungen eines Beckens durch rachitische Skoliose geschildert sind, geht Le o pold im zweiten Theile der Arbeit auf die Frage ein, welche Veränderungen ein rachitisches Becken erleidet, wenn sich zur Skoliose noch eine Kyphose gesellt. Auf.Grund der Untersuchungen kommt Verfasser zu dem Resultat, dass trotz der durch die Kyphose bedingten, die rachitischen Zeichen abschwächenden Einflïsse das k.-s.-r. Becken doch deutlich noch die Zeichen der Rachitis erkennen lässt und infolge der Skoliosis mehr oder weniger asymmetrisch ist. Der Beckeneingang hat eine annähernd runde Form erhalten. Die Gestalt des Beckenkanals ist eine von oben nach unten trichterförmige, also eine dem rachitischen Typus entgegengesetzte. Die Conjugata vera ist

1) Zur kürzeren Schreibweise möge in Folgendem

$$
\begin{aligned}
& \text { s.-r. Becken = skoliotisch-rachitisches Becken, } \\
& \text { k.-r. }, \quad=\text { kyphotisch-rachitisches " } \\
& \text { k.-s.-r. } " \quad=\text { kyphoskoliotisch-rachitisches Becken }
\end{aligned}
$$

bedeuten. 
im Eingange relativ vorlängert, der gerade Durchmesser im Ausgange relativ verkürzt, bedingt durch eine Rotation des Kreuzbeines um seine quere Achse. Letzteres verläuft gestreckter. Die Distanz der Spinae anteriores superiores ilei ist vergrössert, desgleichen der quere Durchmesser des Eingangs, welcher zum Unterschied von einem rein kyphotischen Becken die Conjugata vera übertrifft. Weitere spätere Untersuchungen Le o p old 's über das s.-r. und k.-s.-r. Becken, die derselbe während einer wissenschaftlichen Reise in den pathologisch-anatomischen Museen von Lyon und Paris vornahm (cf. dieses Archiv, Bd. XVI), bestätigten aufs Genaueste die früheren Ergebnisse. In der Hauptsache zu gleichen Resultaten führten die Untersuchungen von Dumas und Champneys über k.-s.-r. Becken.

Mit Rücksicht darauf, dass die Lehre vom k.-s.-r. Becken noch immer weiteren Ausbaues bedarf, mögen im Folgenden drei Becken aus dem königl. Entbindungsinstitut zu Dresden beschrieben werden, von denen das erste, Becken A, einem kindlichen kyphotischen Skelett angehört, die beiden anderen, Becken $\mathrm{B}$ und $\mathrm{C}$, k.-s.-r. sind, deren Trägerinnen Ende vorigen Jahres bald nach einander in obiger Anstalt zur Geburt kamen und an deren Folgen zu Grunde gingen. Dem Director der Anstalt, Herrn Professor Dr. Leopold, spreche ich für die gütige Ueberlassung des Materials, sowie für die mannigfache Unterstützung bei meiner Arbeit hiermit meinen aufrichtigsten Dank aus.

Es möge in erster Linie das kindliche kyphotisehe Skelett A mit seinen Veränderungen am Becken beschrieben werden und sodann die k.-s.-r. Becken B und C, von denen das letztere das am schärfsten ausgeprägte ist.

\section{Fall (Becken A).}

Das Präparat (s. Taf. I), über dessen Herkunft nichts bekannt ist, besteht aus dem vollständigen Skelett ohne Schädel und stammt von einem etwa 8-10jährigen Mädchen. Von Rachitis findet sich keine Spur: die Extremitätenknochen sind gerade und gracil gebaut. Die Vereinigungsstellen der Darm-, Sitz- und Schambeine in der Pfanne sind noch nicht verknöchert. Zunächst fällt eine hochgradige scharfe Knickung der Wirbelsäule in der Gegend des achten Brustwirbels in die Augen. Während der untere Theil der Wirbelsäule vom Kreuzbein aus bis zum achten 
Brustwirbel in gerader Linie nach oben und etwas nach hinten verläuft, wendet sich der obere Theil der Wirbelsäule von da aus scharf spitzwinkelig nach vorn, zunächst in horizontaler Linie, während die Halswirbelsäule sich wieder Fig. 1. nach unten neigt, wie es die nebenstehende

8. B. $w$.

1. L. $w$.

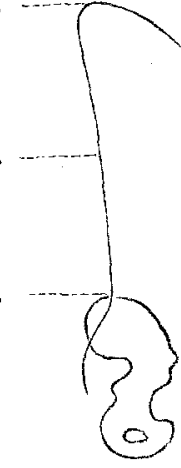

8. B. $w .=$ achter Brustwirbel.

1. $L . w .=$ erster Lendenwirbel.

1.K. $w .=$ erster Kreuzbeinwirbel. Figur 1 veranschaulicht. Um den Grad der Abknickung $\mathrm{zu}$ bestimmen, errichten wir uns auf dem vorderen oberen Rande der Symphyse eine Senkrechte, welche oben den Körper des sechsten Halswirbels trifft. Die Spitze des Höckers liegt von dieser senkrechten in horizontaler Linie $10 \mathrm{~cm}$ weit nach hinten, während das Tuberculum atlant. etwa $5 \mathrm{~cm}$ weit vor derselben liegt. Der Körper des dritten Halswirbels steht senkrecht ïber der rechten Seite des Manubr. sterni und ist von demselben nur $11 / 2 \mathrm{~cm}$ weit entfernt. Auf der Vorderseite wendet sich der Körper des 10. Brustwirbels bereits rechtwinkelig nach vorn. An dieser Stelle sind deutlich Residuen cariöser Processe vorhanden. Das Brustbein ist nach der linken Seite verschoben und mit dem unteren Theile nach links geneigt. Dasselbe ist von oben nach unten convex, seine untere Spitze steht in gleichem Niveau mit den Spinae ilei ant. sup. Der Thorax ist ron rechts nach links comprimirt. Die Rippen verlaufen senkrechter, die beiden ersten direct senkrecht nach unten.

Betrachten wir jetzt, welche Veränderungen bereits am kindlichen Becken durch diese Kyphose entstanden sind. Dabei hat man sich jedoch vorerst zu erinnern, dass die normalen Becken von Neugeborenen und von Kindern in den ersten Jahren in mancher Beziehung den erwachsenen kyphotischen Becken sehr ähnlich sind. Nach den Untersuchungen von Litzman $n$ verläuft nämlich bei Neugebornen das Kreuzbein gestreckter und ist verhältnissmässig schmäler, als beim Erwachsenen. Das Promontorium steht sehr hoch; der gerade Durchmesser ist im Verhältniss zum queren vergrössert, wodurch der Beckeneingang eine runde, sogar längsovale Form bekommt. Sämmtliche Durchmesser werden nach dem Beckenausgange hin kleiner. 
Fehling kommt zwar nach seinen Untersuchungen an Becken von Neugeborenen und Föten zu einem etwas anderen Resultat. Nach ihm ist bereits beim normalen neugeborenen Becken eine gewisse Querspannung vorhanden, die freilich geringer ist, als beim Erwachsenen. Das Verhältniss des geraden Durchmessers des Eingangs zum queren ist nach $\mathrm{F}$ ehling beim weiblichen neugeborenen Becken wie 1,00:1,19, nach Litzmann wie 1,00:1,07, während beim Erwachsenen sich beide Durchmesser wie 1,00:1,29 verhalten. Fehling hält neugeborene Becken mit rundem Eingang für sehr selten und die mit längsovalem geradezu für pathologisch. Er bezeichnet aber auch den Charakter des Beckens von Neugeborenen als eines nach dem Ausgange zu gleichmässig verengten Trichterbeckens.

Durch den Gebrauch der unteren Extremitäten und den Druck der Rumpflast, sowie durch den Zug der Bänder und Muskeln gestaltet sich nun allmälig das erwachsene Becken aus dem kindlichen heraus. Schon im achten Jahre ist dadurch das Becken deutlich verändert, aber noch im 15. Jahre die definitive Beckenform nicht erreicht. Unser Becken A zeigt dagegen keine Spur von Uebergangsform zum normalen erwachsenen Becken, obgleich mit Sicherheit angenommen werden kann, dass die Trägerin desselben ihre unteren Extremitäten zum Gehen benutzt hat. Es tritt vielmehr schon beim ersten Anblick die exquisit kyphotische Form des Beckens hervor. Das Promontorium steht sehr hoch, in gleichem Niveau mit den Spinae ilei ant. sup. Der obere Theil des Kreuzbeines ist nach hinten gezogen, und ist der Winkel, den dasselbe mit der Lendenwirbelsäule bildet, vergrössert.

Der gerade Durchmesser des Einganges ist dadurch bedeutend vergrössert und grösser als der Querdurchmesser. Die Darmbeinschaufeln und Lineae arcuatae verlaufen gestreckter. Der Beckeneingang hat eine längsovale Form. Sieht man von oben ins Becken hinein, so erscheint dasselbe durch die Annäherung der Kreuzbeinspitze an die Symphyse und die Convergenz der Beckenwände nach unten deutlich trichterförmig.

Diese kyphotischen Veränderungen am kindlichen Becken A werden uns noch deutlicher erscheinen, wenn wir die drei Beckendurchschnitte graphisch construiren und dieselben mit einem gleichalterigen kindlichen skoliotisch-rachitischen Becken und einem etwa gleichalterigen normalen kindlichen Becken vergleichen.

Skelett und Becken eines 8 jährigen skoliotisch-rachitischen 
Mädchens ist von Leopold (l. c.) unter $S_{1}$ beschrieben worden, während wir für ein normales kindliches Becken die Maasse von Litzmann benutzen, welche derselbe in seinem Werke: „Die Formen des Beckens" für ein normales 6jähriges Kind angegeben hat.

Die folgenden Diagramme sind nach dem Vorgange B reisky's in halber natürlicher Grösse construirt und bezeichnen mit der geraden Linie das normale kindliche Becken nach Litzmann, mit der punktirten Linie das kindliche s.-r. Becken (Le opold $\mathrm{S}_{1}$ ) und mit der gestrichelten Linie das kindliche kyphotische Becken A der Dresdener Sammlung.

In Fig. 2 sind die Sagittalebenen der drei Becken zusammengestellt. $h h$ stellt die Horizontale dar, $N N$ die Richtung der Normalconjugata; mit $M$ werden die Endpunkte der Normalcon-

Fig. 2.

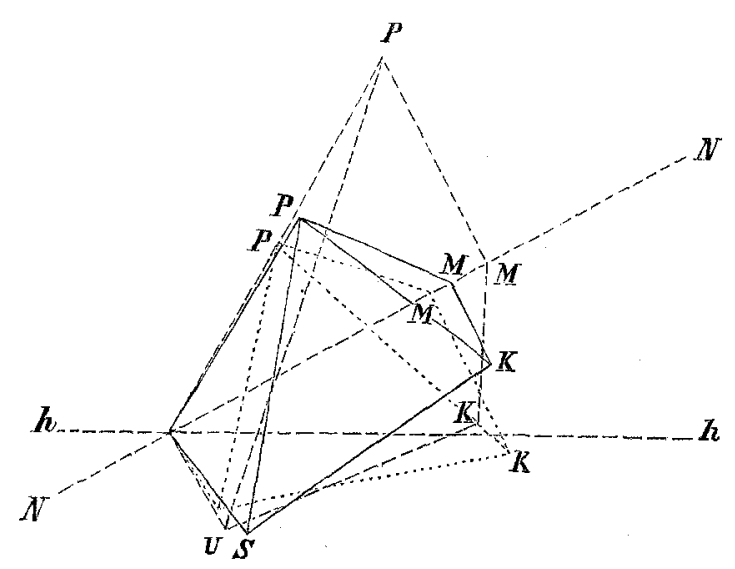

jugata an der Mitte des dritten Kreuzbeinwirbels in den verschiedenen Becken bezeichnet. $P=$ Promontorium. $S . P=$ Symphysis pubis; $U . S=$ Unterer Symphysenrand; $K=$ Kreuzbeinspitze. Die absoluten und procentuarischen, auf die Basis des Kreuzbeines $=100$ bezogenen Maasse sind in den beifolgenden Tabellen angegeben.

Bei der Betrachtung der Sagittalebene dos kindlichen Beckens fällt uns zunächst die bedeutend vergrösserte Conjugata vera des Einganges auf, welche nur um 2,1 cm kürzer ist, als beim erwachsenen normalen Becken und den geraden Durchmesser des Ausganges 
und zum kyphoskoliotisch-rachitischen Becken.

um 40 Proc. übertrifft. Bei dem normalen kindlichen Becken ist die Conjugata bedeutend kleiner; am auffallendsten sind jedoch

Fig. 3.

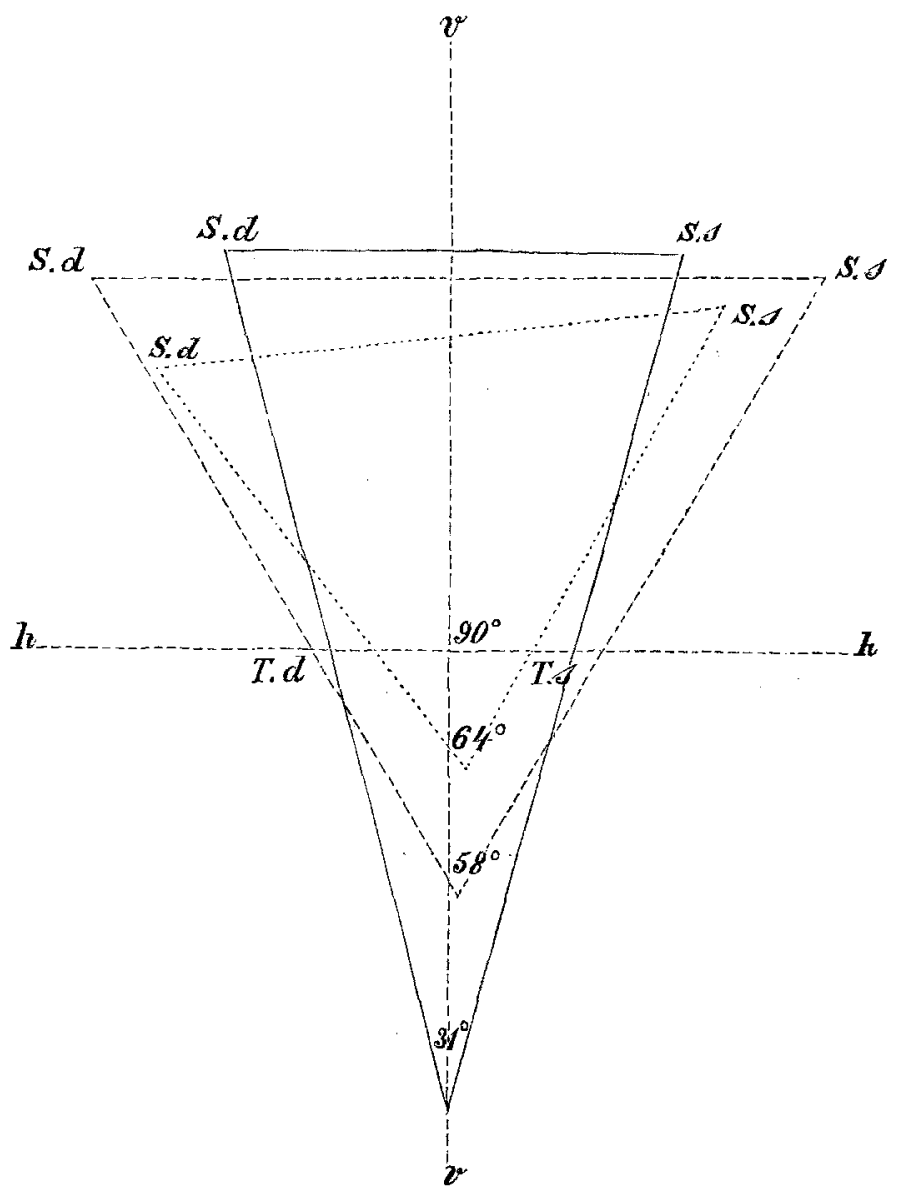

$v v=$ Verticale.

$S . d .=$ Spina ilei anterior superior dextra.

$S . s .=\quad, \quad, \quad, \quad$ sinistra.

T. $d .=$ Tuber ischii dextrum.

T. $s .=\quad " \quad$ sinistrum.

die Unterschiede zwischen unserem kyphotischen Becken A und dem s.-r. (Leopold $S_{1}$ ). Bei letzterem beträgt die Conjugata vera des Einganges nur $4 \frac{1}{2} \mathrm{~cm}$, ungefähr die Hälfte vom Becken A, während der gerade Durchmesser des Ausganges den des Einganges 
um 25 Proc. übertrifft. Ferner sehen wir an der Fig. 2 die relative Verlängerung und Streckung des Kreuzbeines: das absolute Maass der vorderen Kreuzbeinhöhe beträgt, in gerader Linie gemessen, im Becken $A 7,7 \mathrm{~cm}$, im $S_{1}$ nur $4,7 \mathrm{~cm}$.

Die Normalconjugata ist am Becken A dem kyphotischen Typus entsprechend verkürzt; sie ist um 19 Proc. kleiner, als die Conjugata vera; im kindlichen Becken $S_{1}$ ist sie dagegen dem rachitischen Typus gemäss vergrössert und um 25 Proc. grösser, als die Conjugata vera.

Auch in den beiden anderen Ebenen, der frontalen und horizontalen, sowie aus den Maassverhältnissen des Beckeneinganges zur Mitte und Ausgang manifestirt sich der kyphotische Charakter des Beckens A und tritt der Unterschied desselben von dem Becken $S_{1}$ und dem normalen kindlichen Becken klar hervor.

Fig. 3 stellt als frontaler Durchschnitt das Verhältniss der Tubera ischii zu den Spinae ilei ant. sup. dar.

Die Distanz der Spin. ilei ant. sup. im Becken A ist gegenüber dem normalen und rachitischen kindlichen Becken auffallend erweitert und im Verhältniss zu dieser Entfernung ist der quere Durehmesser des Ausganges relativ verengert. Die Spinae ilei ant. sup. sind im kyphotischen Becken A um 129 Proc., im normalen kindlichen Becken nach Litzmann nur um 82 Proc. grösser als der Querdurchmesser des Ausganges.

Auch der vordere Querdurchmesser ist dem kyphotischen Charakter entsprechend beim Becken A dem Querdurchmesser des Ausganges gegenüber vergrössert, um 14 Proc., während derselbe beim Becken $S_{1}$ nur um 8 Proc. grösser ist, als der quere Durchmesser des Ausganges. Die Hüftstachelsitzknorrenlinien sind im kindlichen kyphotischen Becken vergrössert, desgleichen ist der Winkel, den beide mit einander bilden, grösser als am normalen Becken.

An der dritten Ebene, der horizontalen, tritt zunächst die längsovale Form des Beckeneinganges vom Becken $\mathrm{A}$ hervor, wie es auch bei erwachsenen kyphotischen Becken der Fall ist, indem die Conjugata vera den queren Durchmesser im Eingange an Grösso übertrifft. Im Gegensatze dazu ist die Beckeneingangsform bei dem Litzman n'schen kindlichen Becken eine mehr querovale, während das kindliche rachitische Becken $S_{1}$ eine ebenfalls von vorn nach hinten abgeplattete, zugleich aber asymmetrische, schräg verschobene Form hat. Der kyphotische Charakter des Beckens A spricht sich 
und zum kyphoskoliotisch-rachitischen Becken.

ferner aus in der Streckung der beiden Lineae terminales, in der relativen Vergrösserung des vorderen Querdurchmessers, sowie in

Fig. 4.

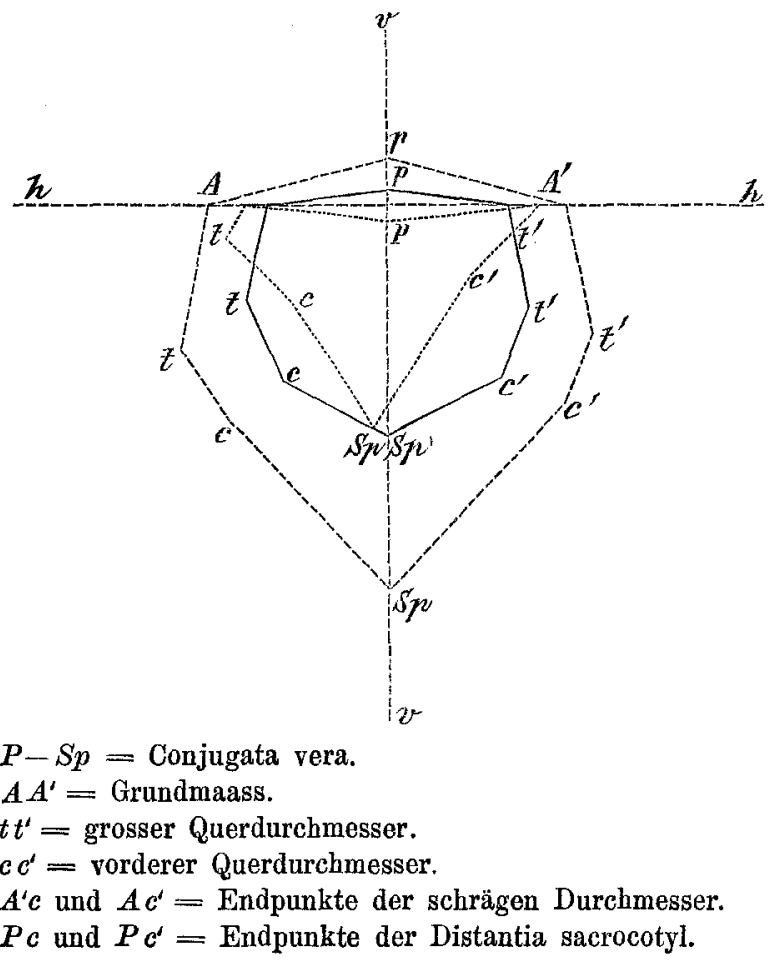

dem vergrösserten Abstande des grossen Querdurchmessers des Einganges vom Kreuzbein.

Folgende Tabelle zeigt uns das Verhältniss der Durchmesser im Eingang, Höhle und Ausgang an den drei Becken zu einander:

\begin{tabular}{|c|c|c|c|c|}
\hline Durchmesser & & $\begin{array}{c}\text { Normales } \\
\text { weibliches } \\
\text { kindliches } \\
\text { Becken } \\
\text { Litzmann. }\end{array}$ & $\begin{array}{l}\text { Skoliotisch- } \\
\text { rachitisches } \\
\text { kindliches } \\
\text { Becken } \\
\text { Leo pold. }\end{array}$ & $\begin{array}{l}\text { Kyphotisches } \\
\text { kindliches } \\
\text { Becken A. }\end{array}$ \\
\hline Gerader & $\begin{array}{l}\text { Eingang } \\
\text { Höhle } \\
\text { Ausgang }\end{array}$ & $\begin{array}{l}5,05 \\
6,86 \\
-\end{array}$ & $\begin{array}{l}4,50 \\
5,46 \\
6,0\end{array}$ & $\begin{array}{l}9,2 \\
7,0 \\
5,8\end{array}$ \\
\hline $\begin{array}{c}\text { Grösster } \\
\text { querer }\end{array}$ & $\begin{array}{l}\text { Eingang } \\
\text { Höhle } \\
\text { Ausgang }\end{array}$ & $\frac{5,5}{5.5}$ & $\begin{array}{l}5,46 \\
3,0 \\
3,48\end{array}$ & $\begin{array}{l}8,0 \\
\mathbf{5 , 8} \\
\mathbf{5 , 6}\end{array}$ \\
\hline
\end{tabular}


Es ergiebt sich daraus eine constante Abnahme der beiden Hauptdurchmesser vom Eingange bis zum Ausgange beim kindlich kyphotischen Becken A, während das kindliche rachitische Becken $\mathrm{S}_{1}$ das entgegengesetzte Verhalten zeigt.

Aus alledem aber zeigt sich, dass schon das kindliche Becken deutliche, durch die Kyphose bedingte Veränderungen an sich trägt, welche dem kindlich s.-r. Becken diametral entgegengesetzt sind.

Fig. 5.

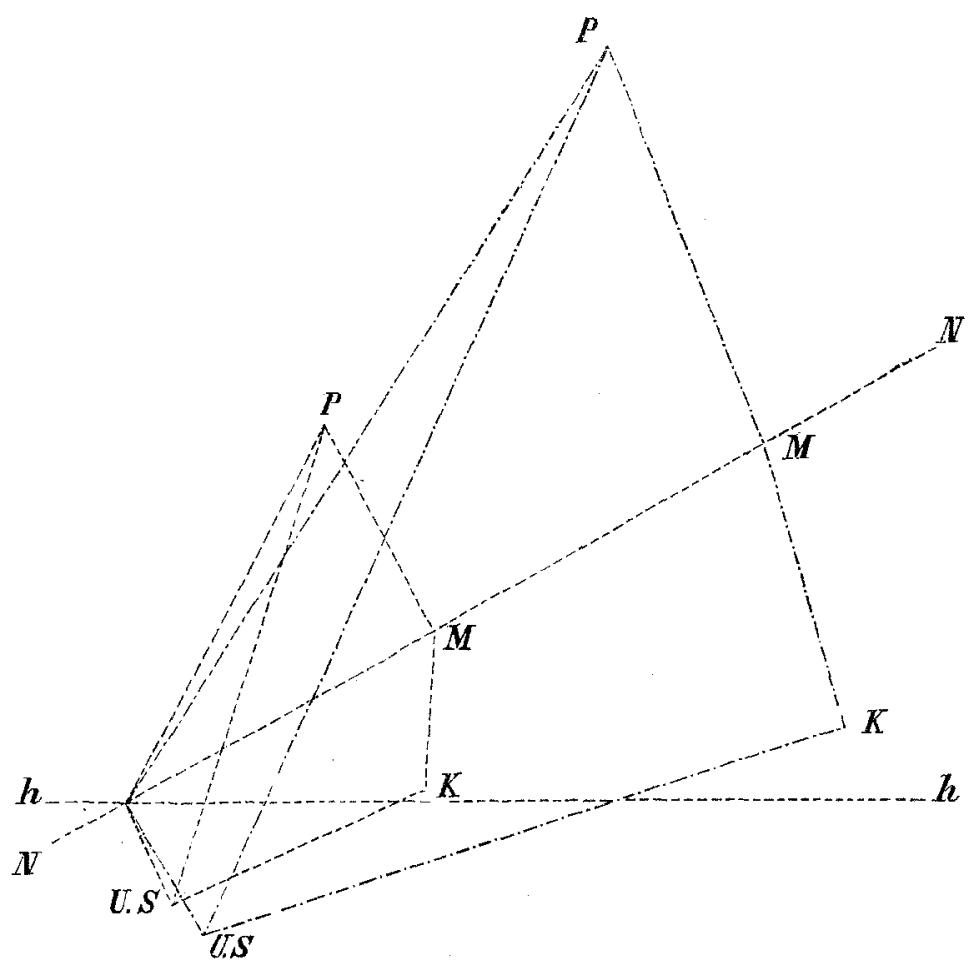

In Fig. 5 ist die Sagittalebene des Beckens A mit der des erwachsenen kyphotischen Beckens Nr. 15 von Breisky zusammengestellt, wobei sich eine auffallende Aehnlichkeit beider zeigt, indem das Becken A gewissermaassen das verkleinerte Bild des Beckens Breisky Nr. 15 darstellt.

Wenn sich nun zur Rachitis eine Kyphose oder Kyphoskoliose hinzugesellt, so werden wir aus dem Vorhergehenden verstehen, wie dadurch die rachitischen Zeichen am Becken abgeschwächt 
und umgeändert werden. Der Grad der Umänderung hängt selbstverständlich von dem Grade und Sitze der Kyphose ab, sowie von der Zeit der Entstehung des Höckers.

Es möge jetzt die Beschreibung der beiden erwachsenen k.-s.-r. Becken folgen, und zwar zunächst des Beckens B, welches die geringeren Abschwächungen durch die Kyphose zeigt.

\section{Fall. (Becken B.)}

Ernestine N...., 35 Jahre, Fabrikarbeiterin, IUpara, trat am 11. December 1883 als Kreissende in das Entbindungsinstitut zu Dresden ein. Sie litt als Kind an Rachitis und lernte erst im dritten Jahre laufen. Menstruirt ist sie mit dem 22. Jahre. Erste Geburt 1876; zweite Geburt 1880. Der Verlauf derselben ist nicht näher angegeben. Letzte Menstruation Ende Februar. - Die Kreissende ist $128 \mathrm{~cm}$ gross. Die Lünge des Thorax vom Manubrium sterni bis zur 12. Rippe beträgt beiderseits $23 \mathrm{~cm}$, die Beinlänge (Trochanteren bis zur Sohle) beiderseits $76 \mathrm{~cm}$. Die Knochen der Extremitäten sind plinmp gebaut, nicht verkrïmmt. Die Wirbelsäule ist k.-s. verbogen, und zwar zeigt der obere Theil der Wirbelsäule bis zum siebenten Brustwirbel eine Verbiegung nach rechts und hinten, der untere Theil ist compensatorisch nach links verbogen. Es besteht ein starker Hängebauch. Das Kind lag in zweiter Schädellage und wurde in derselben nach 10 stündiger Geburtsdauer bei kräftigen Wehen spontan geboren. Gewicht desselben betrug $3550 \mathrm{~g}$, Länge $51 \mathrm{~cm}$. Der Kopf war lang ausgezogen, rechtes Scheitelbein abgeflacht; grosse Kopfgeschwulst am Hinterhaupt. Am zweiten Tage des Wochenbettes bekam die Wöchnerin hohes Fieber $\left(40^{\circ} \mathrm{C}\right.$.) und vermehrte Pulsfrequenz (132). Das Fieber stieg am dritten und vierten Tag auf $40,2^{\circ}$ C. und fiel am fünften und sechsten Tage, während die Pulsfrequenz zunahm. Am sechsten Wochenbettstage starb die Wöchnerin unter den Erscheinungen acutester Sepsis, ohne dass je grosse Empfindlichkeit des Leibes aufgetreten wäre, und unter zinnehmendem Meteorismus und dyspnoischen Erscheinungen. Die von Herrn Medicinalrath Dr. Birch-Hirschfeld vorgenommene Section ergab als Diagnose: Septische Peritonitis, Pleuritis, beginnende $\mathrm{Me}-$ ningitis.

Das getrocknete Becken (s. Taf. III, Fig. 2), an welchem die vier untersten Lendenwirbel noch vorhanden sind, trägt unverkennbar die Spuren der Rachitis an sich. Es ist sehr plump gebaut und zeigt verschiedene scharfe Knochenleisten und knöcherne Excrescenzen. Die Darmbeinschhaufeln sind klein, liegen flach und sind mehr frontal gestellt. In der Mitte sind sie abnorm verdünnt. Die Spinae ilei ant. sup. stehen weit auseinander und iibertreffen die Entfernung der Cristae ilei. Die Pfannen 
sehen mehr nach vorn; die absteigenden Schambeinäste sind nach aussen umgebogen; der Schambogen ist viel weiter als normal. Der Lendentheil der Wirbelsäule ist nach links abgebogen und durch eine rechtsseitige Kyphoskoliose der Brustwirbel compensirt. Maasse:

Den Grad der unteren Lendenskoliose erläutern folgende Vorn:

Vordere Mitte des zweiten Lendenwirbels, Spin. ilei ant. sup. dextr. $=20,7 \mathrm{~cm}$. Lendenwirbels, Spin. ilei

$$
\begin{aligned}
\text { ant. sup. sinistr. } & =14,5 \\
\text { Differenz } & =6,2 \mathrm{~cm} .
\end{aligned}
$$

Hinten:

Processus spin. des zweiten Lendenwirbels, Spin. ilei

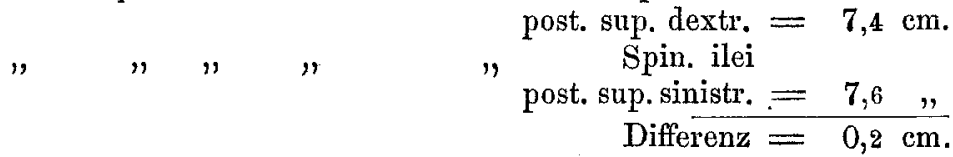

Processus spin. des zweiten Lendenwirbels, Spin. ilei ant. sup. dextr. $=19,5 \mathrm{~cm}$. $" \quad, \quad " \quad$, Spin. ilei
ant. sup. sinistr. $=20,0 \quad "$,
Differenz $=0,5 \mathrm{~cm}$.

Auf der Rückseite treten also die Abweichungen der Lendenwirbel viel weniger deutlich hervor. Die Processus spinosi der Lendenwirbel verlaufen vom Processus spinosus des ersten Kreuzwirbels an fast in einer senkrechten Linie nach oben.

Da die Neigung des Beckens an der Lebenden nicht bekannt ist, so geben wir demselben eine normale Neigung und errichten in dieser Stellung auf die Schamfuge eine Senkrechte. Dieselbe trifft den unteren Theil des dritten Lendenwirbels an dessen rechter Seite. Von hier aus wendet sich der obere Theil der Lendenwirbelsäule bereits wieder nach hinten und rechts.

Die Lendenwirbel sind also nach links geneigt und torquirt. Der linke Processus transversus des untersten Lendenwirbels liegt dem des obersten Kreuzbeinwirbels und dem Darmbein oberhalb der Articulatio saeroiliaca direct-auf; die folgenden Processus transversi stehen auf der linken Seite steiler als auf der rechten. Die zu einer Articulation gehörigen Processus obliqui klaffen auf der linken Seite auseinander, während sie auf der rechten 
Seite sich eng berühren, zwischen dem zwoiten und dritten Lendenwirbel sogar knöchern vereinigt sind.

Da die Abweichungen der Wirbelsäule nach rechts und links ziemlich gleichmässig sind und dadurch keine stärkere Belastung des Beckens auf einer Seite stattgefunden hat, da ferner beide Extremitäten gleichzeitig und gleichmässig zum Gehen gebraucht sind, so werden wir ein ziemlich symmetrisches Becken erwarten. Ferner ist zu erwähnen, dass der Einfluss der Kyphose auf die Beckengestalt, speciell auf das Kreuzbein, wie schon Breisky angiebt, um so bedeutender ist, je tiefer der Höcker sitzt. Demnach müssen in unserm Becken wegen der hochsitzenden Kyphosis die kyphotischen Erscheinungen weniger ausgeprägt sein.

Wie die folgenden Betrachtungen zeigen, ist jedoch die kyphotische Veränderung am Becken $\mathbf{B}$ neben der rachitischen eine unverkennbare.

Das $\mathrm{Kreuzbein}$ ist wie beim rein kyphotischen Becken verschmälert, die linke Hälfte ist schmäler als die rechte. Die Spitze des Kreuzbeines liegt dem Tuber und der Spina ischii auf der rechten Seite näher, als auf der linken. Das ganze Kreuzbein ist der Länge nach concav, zeigt aber nicht die für Rachitis charakteristische Abknickung des unteren Theiles nach vorn. Der Quere nach macht sich eine geringe rachitische Convexität der Wirbel geltend. Das Promontorium steht für ein rachitisches Becken ungewöhnlich hoch, im gleichen Niveau mit der Linea arcuata und ragt weniger stark in den Beckeneingang hinein. Der Schamfuge steht es gerade gegenüber. Dadurch, dass der obere Theil des Kreuzbeines durch die Kyphose etwas nach hinten und oben gezogen ist, sind die Darmbeine hinten auseinandergedrängt und ist infolge dessen der Abstand der Spinae ilei post. sup. ein grösserer geworden. Die Dornfortsätze des Kreuzbeines gehen ohne wesentliche Einknickung in die der Lendenwirbel über.

Die beiden Beckenhälften sind infolge der gleichmässigen Belastung auch von annähernd gleicher Form und Neigung. Es fehlt die bei asymmetrischen Becken charakteristische stärkere Hebung, Sagittalstellung und geringere Neigung der Beckenhälfte auf der Seite der Skoliolordose. Während nun infolge der Kyphose die Darmbeine hinten durch das Kreuzbein auseinandergedrängt sind, haben aus derselben Ursache durch die stärkere Spannung der Ligamenta ileofemoralia diè Sitz- und Schambeine sich ein- 
ander genähert. Die Seitenwände des kleinen Beckens convergiren daher von oben nach unten beträchtlich.

Auch bei diesen Becken construiren wir die Diagramme der drei verschiedenen Ebenen und vergleichen dieselben mit dem normalen und dem s.-r. Becken. In den folgenden Figuren bedeuten die gestrichelten Linien unser k.-s.-r. Becken B, während die ausgezogenen Linien das normale Becken, die punktirten Linien das s. r. Becken bezeichnen. Figurenbezeichnung wie früher.

Aus Fig. 6 ergiebt sich:

1) Die Conjugata vera ist kürzer als normal (um 1,6 cm); dem s.-r. Becken gegenüber ist sie jedoch vergrössert, da bei demselben die Werthe zwischen $5^{1} / 2^{-}-8^{1} / 4 \mathrm{~cm}$ schwanken. Wäre

Fig. 6 .

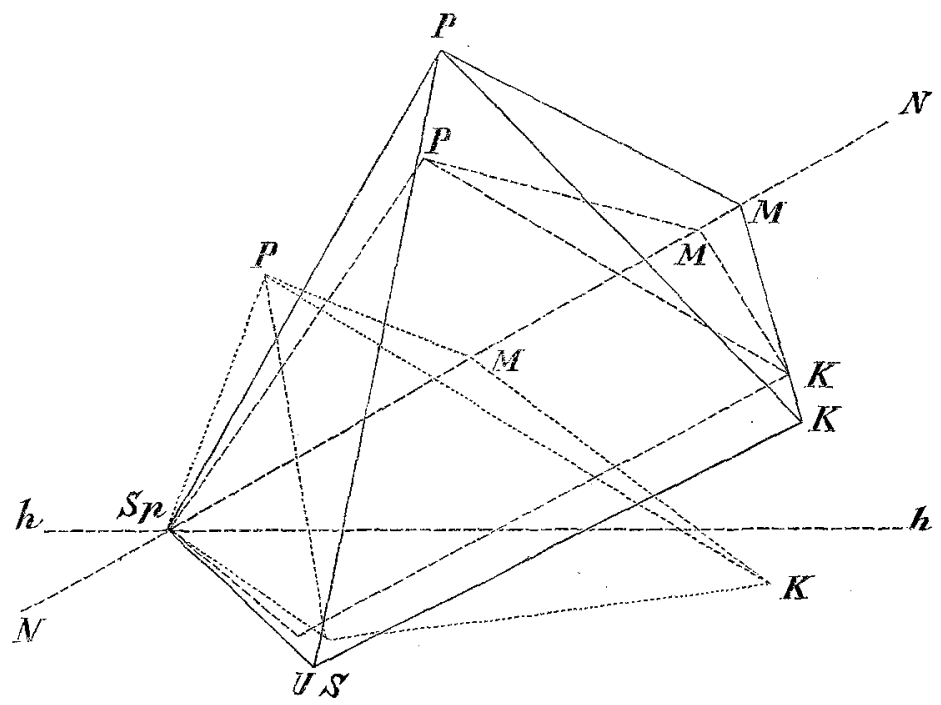

die hochgradige rachitische Skoliose nicht mit Kyphose verbunden, so wäre jedenfalls eine viel bedeutendere Verengerung der Conjugata vera zu Stande gekommen, wie wir es an analogen rein s.-r. Becken sehen. So aber hat der Einfluss der Kyphosis eine erheblichere Verengerung verhindert.

2) Der gerade Durchmesser des Ausganges ist vergrössert sowohl absolut als auch relativ. Er übertrifft das normale Maass um 1,1 cm, und die Conjugata vora um $3,2 \mathrm{~cm}$. Dieses Ver- 
halten ist etwas auffällig, da es dem s.-r. Typus gleicht, während im Allgemeinen bei k.-s.-r. Becken das entgegengesetzte Verhalten stattfindet. Der Grund dafür dürfte wohl in dem hohen Sitze der Kyphose zu suchen sein, welche diese rachitische Veränderung nicht zu modificiren vermochte und nur einen Zug auf die obere Hälfte des Kreuzbeines ausübte.

Die Normalconjugata ist wie beim rachitischen Becken vergrössert; sie übertrifft die Conjugata vera um 33 Proc., jm normalen Becken um 19 Proc.

Bei der Betrachtung der Frontalebene (Fig. 7) und der betreffenden Maasstabellen zeigen sich folgende bemerkenswerthe Punkte:

1) Die Distanz der Spinae ilei ant. sup. ist relativ vergrössert. Sie zeigen den kyphotischen Typus dadurch, dass sie das normale Maass um 68 Proc. übertreffen, während sie im rachitischen Becken nur um 25 Proc. grösser sind. Für die Rachitis charakteristisch ist die um 2 Proc. geringere Distanz der beiden Cristae vor der Distanz der Spinae.

2) Der vordere Querdurchmesser im Eingange ist dem kyphotischen Typus entsprechend vergrössert. Derselbe ist im s.-r. Becken nach den Maassen von Leopold um 34, 5 bis 10,5 Proc. kleiner, in unserm Becken $B$ um 7,5 Proc. grösser als normal. Die Spinae ant. sup. übertreffen den vorderen Querdurchmesser um 158 Proc., im s.-r. Becken um 121 Proc., im normalen Becken um 97,5 Proc.

3) Der quere Durchmesser des Ausganges ist verkleinert; derselbe ist um $21 / 2 \mathrm{~cm}$ absolut kleiner als normal und zeigt den kyphotischen Charakter ferner darin, dass derselbe um 40 Proc. kleiner ist, als der grösste Querdurchmesser im Eingange, während er im normalen Becken durchschnittlich um 14 Proc., im rachitischen um 2-10 Proc. kleiner ist. Mit der Distanz der Spinae ilei ant. sup. verglichen, welche im normalen Becken um 102,5 Proc. grösser sind, als der Querdurchmesser des Ausganges, finden wir in unserem Becken B die Spinae ilei ant. sup. um 178 Proc. grösser. Im kyphotischen Becken Breisky Nr. 15 sind sie um 184 Proc., im s.-r. Becken um 114 Proc., im einfach rachitischen Becken (Breisky Nr. 4) um 118 Proc. grösser, als der Querdurchmesser des Ausganges. Daraus folgt, dass die beiden Hüftstachelsitzknorrenlinien im Becken B unter 
einem weniger spitzen Winkel convergiren, als beim normalen Becken.

4) Die Hüftstachelsitzkn orrenlinien sind um 17 Proc.

Fig. 7.

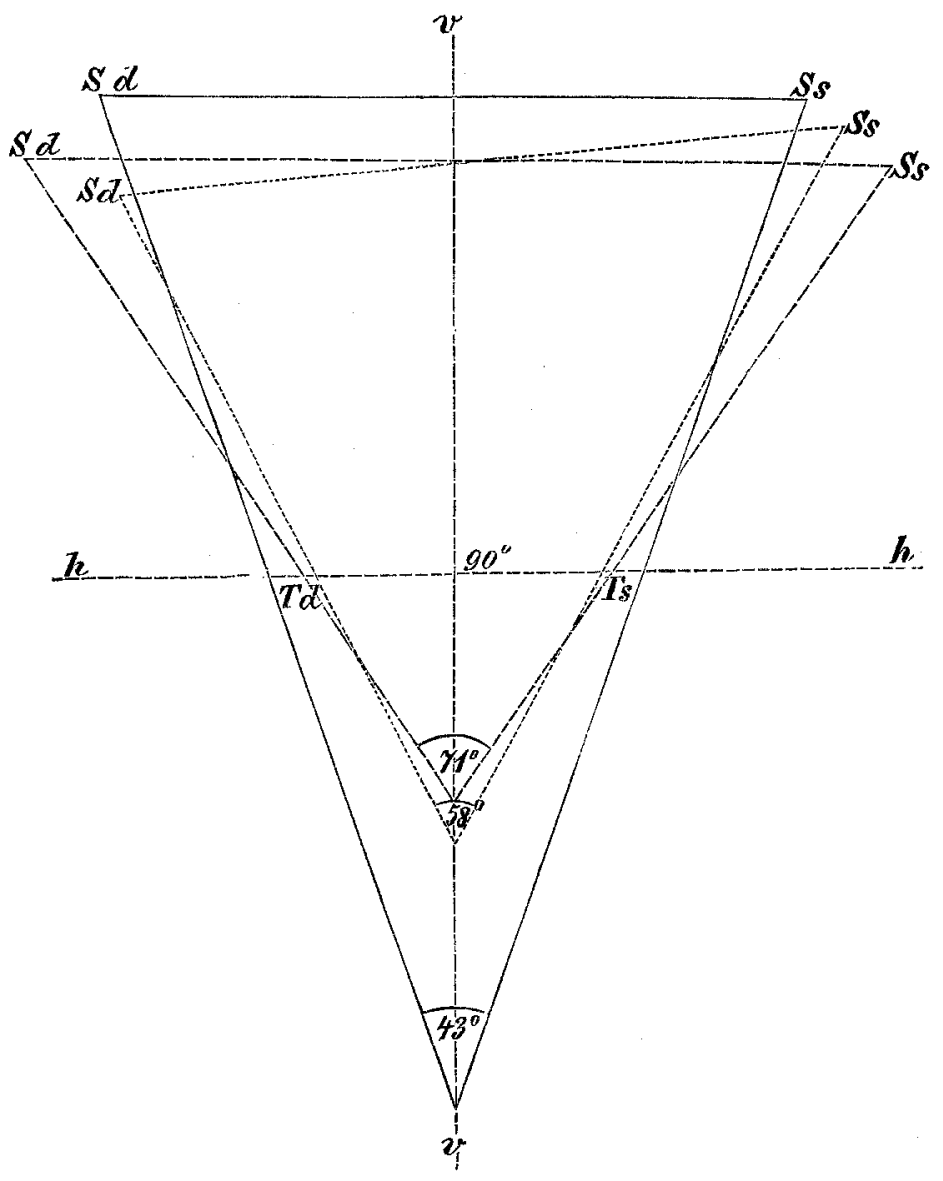

grösser als normal, während sie in den von Leopold beschriebenen rachitischen Becken fast durchweg kleiner sind, als normal.

Die dritte Ebene, die horizontale, zeigt als wesentlichen Unterschied des k.-s.-.r. Beckens B von dem s.-r. die relative Vergrösserung der Conjugata vera des Einganges, die zwar kleiner ist, als normal, jedoch die eines rein s.-r. Beckens bedeutend übertrifft, was, wie oben bereits erwähnt, durch den Einfluss der 
Kyphosis entstanden ist. Derselben Ursache ist auch die Verschmälerung der Kreuzbeinbasis zuzuschreiben, wobei jedoch eine gewisse rachitische Convexität der Quere nach geblieben ist. Ferner ist der grosse Querdurchmesser kleiner als beim s.-r. Becken; doch ist derselbe, weil noch ein gewisser Grad von vermehrter rachitischer Querspannung vorhanden ist, immerhin verhältnissmässig grösser, als bei einem rein kyphotischen Becken.

Fig. 8 .

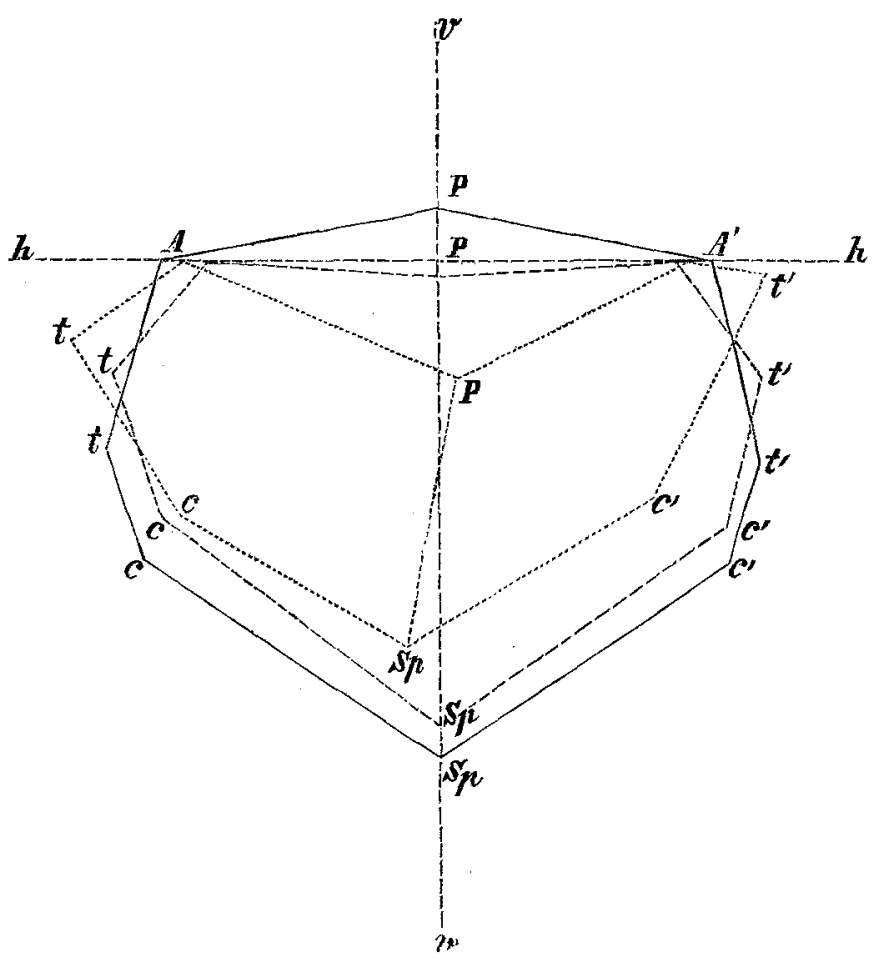

Er ist daher bedeutend grösser als die Conjugata vera und liegt ausserdem dem Kreuzbein näher als normal. Vom vorderen Querdurchmesser liegt derselbe in unserem Becken nicht auffallend weit entfernt, während bei den meisten der beschriebenen k.-s.-r. Becken beide Querdurchmesser des Einganges erheblich auseinander liegen. Der Beckeneingang hat demnach eine querovale, von vorn nach hinten etwas abgeplattete Form. Im Uebrigen ist eine bemerkenswerthe Asymmetrie nicht vorhanden. Die Conjugata vera theilt vielmehr das Becken in zwei gleiche Hälften. 
Das Becken ist also, um das Resultat nochmals zusammenzufassen, durch die Kyphose im geraden Durchmesser des Einganges erweitert, an den seitlichen Theilen von oben nach unten trichterförmig verengt. Die rachitische Querspannung ist etwas abgeschwächt, während im geraden Durchmesser des Ausganges die rachitische Frweiterung durch die Kyphose nicht beeinflusst worden ist. Mit anderen Worten: die Kyphose ist auf die Form des Beckens, welches durch die Rachitis jedenfalls hochgradig verengt worden wäre, von entschieden corrigirendem Einflusse gewesen.

Bei weitem ausgeprägter sind die kyphotischen Erscheinungen im folgenden k.-s.-r. Becken:

\section{Fall. (Becken C.)}

Therese V..., 35 Jahre alt, Ipara, wurde am 26. November 1883 in die Dresdener Entbindungsanstalt aufgenommen. Als Kind war sie immer schwach gewesen und hatte verschiedene Kinderkrankheiten durchgemacht. Eltern und zwei Geschwister sind an Schwindsucht, eine Schwester an einer Rückenmarkskrankheit gestorben. Im vierten Jahre ist sie aus einem Wagen gefallen, infolge dessen sich eine Anschwellung am Rücken bildete, die allmälig grösser wurde. Mit dem neunten Jahre hat sie an Krïcken das Gehen gelernt und von der Zeit an bis jetzt sich stets derselben bedient. Menstruirt ist sie seit dem 22. Lebensjahre. Letzte Menstruation Anfang März 1883. Seit der letzten Zeit leidet die Schwangere häufig an Athembeschwerden, namentlich in Rückenlage; dieselben sind bedingt durch eine hochgradige Kyphoskoliose der Brustwirbelsäule und abnorme Verengerung des Thorax, besonders von einer Seite zur anderen. Der Rumpf ist im Verhältniss zu den Extremitäten ungewöhnlich klein, der Kopf ist nach vorn und unten gesunken und ruht mit dem Kinne auf der Brust. Diese Veränderungen, sowie ein hochgradiger Hängebauch, der fast bis zu den Knieen reichte, und die Kleinheit der Person forderten zu einer genauen Beckenmessung auf, die in der Hauptsache eine Verengerung des Beckenausganges ergab. Die Frucht lag in zweiter Schädellage B. Am 1. December traten die ersten Wehen ein, nachdem die Blase in der Nacht vorher gesprungen war. Später lag das Kind in zweiter Schädellage A; der Kopf stand fest im Beckeneingange, kleine Fontanelle rechts vorn, kindliche Herztöne rechts unten, regelmässig. Die Wehen waren kräftig, so dass am 2. December Morgens 4 Uhr bei völlig erweitertem Muttermunde der Kopf auf dem Beckenboden stand mit rechts vorn stehender kleiner Fontanelle. Hier blieb jedoch der Kopf fest zwischen den beiden Sitzbeinhöckern eingekeilt stehen, welche beiderseits am kindlichen Schädel starke Impressionen verursachten. Grosse Kopfgeschwulst, kindliche Herztöne normal. Dà der Kopf trotz kräftiger 
Wehenthätigkeit von hier aus nicht weiter rückte und der Zustand für die ganz verkrüppelte Person, welche die ganze Geburt bisher im Hocken mit kreuzweise untergeschlagenen Beinen durchgemacht hatte und sehr cyanotisch geworden war, durch Nachlassen der Kräfte sich immer ernster gestaltete, so wurde um sieben Uhr Morgens in Chloroformnarkose die Zange angelegt. Kaum aber hatte die Frau begonnen, unter dem Chloroformapparat zwei Athemzïge zu thun, als Puls und Athmung ganz plötzlich bei ihr aufhörten. Alle sofort angestellten Wiederbelebungsversuche blieben erfolglos. Schnell wurde das Kind entwickelt, doch war es so tief asphyktisch, dass auch bei ihm die Wiederbelebungsversuche ohne Erfolg waren. Es war $3340 \mathrm{~g}$ schwer und $52 \mathrm{~cm}$ lang.

Die von Herrn Medicinalrath Dr. Birch-Hirschfeld vorgenommene Section der Verstorbenen ergab Folgendes:

Beide Lungen infolge der Thoraxdeformität, namentlich im Durchmesser von oben nach unten verkleinert, in den oberen Lappen emphysematisch, überall lufthaltig, mässig bluthaltig und ödematös.

Das Herz liegt mit seinem Längsdurchmesser horizontal, mit der Spitze nach links. Rechter Ventrikel liegt vor, ist dilatirt und erheblich hypertrophisch; linker Ventrikel contrahirt, leer. Mitralis etwas verdickt. Am Pericardium viscerale einzelne feine Hämorrhagien.

Die Leber ist durch eine tiefe quere, durch den Druck der Rippen entstandene Furche, die am stärksten am rechten Lappen ist, eingekerbt. Der Durchmesser der Leber ist von vorn nach hinten vermindert, von oben nach unten vermehrt.

Milz klein, anämisch.

Rechte Niere liegt abnorm hoch, hinter und zum Theil über der Leber. Der Hilus der Niere ist nach unten gerichtet. Der Längsdurchmesser steht quer. Linke Niere, sowie der Durchschnitt beider ist normal.

Uterus ist stark nach vorn geknickt, nicht contrahirt. Die Wand des Corpus uteri ist $2^{1 / 2} \mathrm{~cm}$ dick, blass; Cavum uteri weit, enthält ziemlich reichliches, flüssiges Blut und noch zum grössten Theil die Decidua. Pars cervicalis erheblich verdünnt, an der Innenfläche ausgedehnte Erosionen.

Statt der Symphyse zeigt sich eine alte Diastase der Schambeine, deren Tubera $9 \mathrm{~cm}$ weit von einander stehen, während die medialen Knochenränder ziemlich $3 \mathrm{~cm}$ weit auseinanderklaffen und nur durch Bandmassen hier verbunden sind. Die beiden Beckenhälften sind in hohem Grade an dieser Stelle gegeneinander beweglich. Uebrigens finden sich in der Umgebung der Diastase keine Hämorrhagien noch Zerreissungen, so dass diese Diastase nach der Aussage des Herrn Medicinalrath Dr. BirchHirschfeld als eine langbestandene zu bezeichnen war. 
Das Skelett zeigt eine hochgradige Kyphoskoliose mit Residuen von Spondylitis. Die näheren Verhältnisse werden sich weiter unten bei der Beschreibung des trockenen Präparates ergeben. Zunächst mögen noch einige an der Leiche genommene Maasse erwähnt werden: Die Entfernung vom Manubrium sterni bis zur Symphyse beträgt $31 \mathrm{~cm}$, die Länge der Oberschenkel vom Trochanter major bis zum oberen Rande der Patella $36 \mathrm{~cm}$, die der Unterschenkel von der Tuberositas tibiae bis zur Fusssohle $41 \mathrm{~cm}$. Die gerade Entfernung von der oberen Brustapertur bis zur Crista ilei beträgt $12 \mathrm{~cm}$.

Wenden wir uns jetzt zur Beschreibung des trockenen Präparates.

Dasselbe (s. Taf. III, Fig. 3) besteht aus dem Becken und dem Thorax bis zum zweiten Brustwirbel und trägt folgende Zeichen der Rachitis: 1) die flachliegenden und kleinen Darmbeinschaufeln; 2) den geringen Unterschied der Distanz der Spinae und Cristae ilei (Differenz $1 \mathrm{~cm}$ ); 3) die hochgradige Convexität des Kreuzbeines; ferner die überall hervortretenden scharfen Kanten und Stacheln. Der Schambogen ist sehr weit, die Acetabula sehen nach vorn. Weitere für den Einfluss der Rachitis sprechende Zeichen werden später bei der Betrachtung der verschiedenen Beckenebenen erwähnt werden.

Um den Grad der Kyphose zu bestimmen, geben wir dem Becken eine normale Neigung. Von dem mehr horizontal gestellten Kreuzbein aus und mit diesem einen rechten, nach hinten offenen Winkel bildend, wendet sich die Lendenwirbelsäule bis zur Knickungsstelle nach hinten oben und etwas nach links. Von einer auf den Processus spinosus des fünften Lendenwirbels gefällten hinteren Senkrechten ist der am weitesten nach hinten prominirende Processus spinosus des achten Brustwirbels $16 \mathrm{~cm}$ weit entfernt. Diese Abweichung ist bedingt durch eine enorme cariöse Zerstörung sämmtlicher Brustwirbelkörper bis zum dritten aufwärts, von denen nichts weiter erhalten ist, als eine kaum die halbe Höhe eines normalen Wirbelkörpers erreichende Leiste. Der obere Schenkel der Kyphose wendet sich vom oberen Rande des ersten Lendenwirbelkörpers spitzwinkelig nach vorn und etwas nach rechts. Der dritte Brustwirbelkörper erst ist einigermaassen wieder als solcher erkennbar; derselbe steht direct über der verknöcherten Grenze des ersten und zweiten Lendenwirbelkörpers und ist von derselben $1 \mathrm{~cm}$ weit entfernt. Die drei untersten 
Lendenwirbel sind normal, die beiden obersten zeigen schon in ihren Körpern Zeichen abgelaufener Caries. Die hinteren Bögen der so afficirten Brustwirbel sind wenig oder gar nicht verändert; die Processus spinosi sind einander genähert. Sehr deutlich tritt hinten die rechtwinkelige Stellung des lumbalen Theiles der Wirbelsäule zum Kreuzbein hervor.

Der Thorax erscheint von einer Seite zur anderen comprimirt; die beiden Hälften sind ziemlich symmetrisch. Durch die bedeutende Zerstörung und Compression der dorsalen Brustwirbelkörper sind die Rippen einander genähert und liegen zum Theil dachziegelförmig aufeinander. Die elfte Rippe liegt jederseits der Crista ilei auf.

Wir haben also eine sehr hochgradige, cariös kyphotische, weniger skoliotische Wirbelsäule vor uns, deren Trägerin die $\mathrm{Ky}-$ phosis in früher Jugend erlangt hat. Ausserdem sind deutliche Zeichen von Rachitis vorhanden. Sehen wir jetzt, welche Veränderungen das Becken, speciell seine einzelnen Knochen dadurch erlitten haben.

Das Kreuzbein ist am meisten verändert. Durch den Zug des unteren Kyphosenschenkels ist die obere Hälfte des Kreuzbeines nach hinten und oben gezogen. Das Promontorium steht so hoch über der Linea arcuata, dass eine die Mitte der beiden Cristae ilei verbindende Linie vom Promontorium berührt wird. Hierdurch, sowie durch eine vollständige Streckung der Länge nach unterscheidet es sich wesentlich vom rachitischen. Der Einfluss der Rachitis zeigt sich hingegen an einer bedeutenden Convexität des Kreuzbeines der Länge und Quere nach. Dasselbe erscheint daher als ein gerảder Keil mit gewölbter Vorderfläche. Die Körper traten aus den Flügeln weit hervor. Da die Abweichungen der Wirbelsäule nach den Seiten zu gering sind und sich gegenseitig die Wagschale halten, so ist eine Asymmetrie des Kreuzbeines durch ungleiche Belastung nicht vorhanden. Ebensowenig sind die beiden Beckenhälften asymmetrisch. Der oben erwähnte Symphysenspalt ist durch die Schrumpfung der Bandmassen am trockenen Präparate etwas verringert worden. Das linke Schambein ist in seinem Symphysentheil weiter nach vorn gerückt und steht tiefer als das rechte.

Der Beckeneingang hat eine mehr rundliche Form. Der gerade Durchmesser des Einganges ist vergrössert, desgleichen der quere, der den geraden noch übertrifft. Sehen wir in dem Ver- 
hältnisse dieser beiden Durchmesser des Einganges deutlich den kyphotischen Typus mit dem rachitischen combinirt, so tritt andererseits nach dem Beckenausgange hin die kyphotische Form mehr zu Tage, indem infolge der stärkeren Convergenz der seitlichen Wände des kleinen Beckens, sowie durch die Annäherung der Kreuzbeinspitze gegen die Symphyse eine Trichterform entstanden ist, die noch erheblicher ausgefallen wäre, wenn die beiden Beckenhälften vorn in der Symphyse fest verbunden wären.

Construiren wir wieder die Diagramme der drei Beckenebenen. In den folgenden Figuren ist unser Becken C (gestrichelte Linie)

Fig. 9.

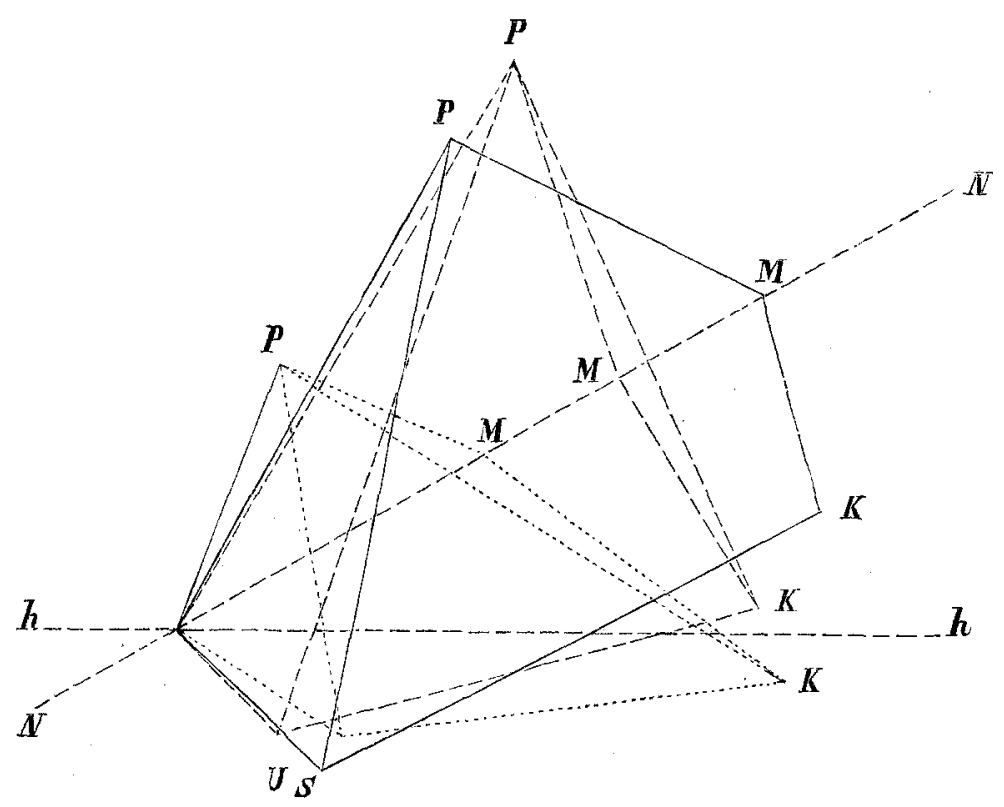

mit dem normalen Becken Breisky Nr. 41 (ausgezogene Linie) und dem rachitischen Becken (punktirte Linie) zusammengestellt. Aus der vorstehenden Fig. 9, der sagittalen Ebene, sowie aus dem Vergleich der absoluten und relativen Maasse der Becken ergiebt sich Folgendes:

1) Die vordere Kreuzbeinhöhe hat dem kyphotischen Typus entsprechend bedentend zugenommen und übertrifft das normale Maass um 16 Proc., das des gewöhnlich rachitischen um 30 Proc. 
2) Die Conjugata vera des Einganges ist dem kyphotischen Charakter gemäss absolut und relativ vergrössert; dieselbe übertrifft die des normalen Beckens um 2,4 cm, procentuarisch um 22,5 Proc.

3) Die Normalconjugata (nach Meyer) ist infolge des Zurückweichens des oberen Theiles des Kreuzbeines und der Convergenz desselben von oben nach unten um 28 Proc. verkleinert, während sie im normalen Becken die Conjugata vera um 19 Proc., im rachitischen um 36 Proc. übertrifft.

4) Der gerade Durchmesser des Ausganges ist nur wenig absolut, relativ dagegen (im Vergleich zur Conjugata vera des Einganges) um 22 Proc. verkleinert. Im normalen Becken übertrifft derselbe den geraden Durchmesser des Einganges um 3,5 Proc.; im rachitischen Becken um 52 Proc.; im rein kyphotischen Becken Breisky Nr. 15 ist derselbe 44 Proc. kleiner als die Conjugata vera. Diese Zahlen zeigen uns deutlich den Einfluss beider Momente, der Kyphosis und der Rachitis, auf die Stellung des Kreuzbeines. Beide Kräfte wirken im entgegengesetzten Sinne; in unserem Falle war die Wirkung der Kyphose eine vorherrschende, so dass eine Annäherung des unteren Theiles des Kreuzbeines an die Symphyse erfolgte, ohne jedoch wegen des Einflusses der Rachitis jenen hohen Grad zu erreichen, wie wir es beim rein kyphotischen Becken finden.

Bei der Betrachtung der Frontalebene (Fig. 10) zeigt sich Folgendes :

1) Die oben erwähnte Vergrösserung der Distantia spinarum ilei anteriorum superiorum um 14 Proc. gegen die des normalen Beckens. Sie werden von der Distanz der Cristae ilei nur um 12 Proc. übertroffen, wodurch sich der rachitische Charakter zeigt, während die Cristae im normalen Becken um 40 Proc. grösser sind, als die Spinae.

2) Der vordere quere Durchmesser ist nur um ein Geringes (3,5 Proc.) kleiner als normal und weicht darin vom s.-r. Becken ab, in welchem derselbe um 34,5-10 Proc. kleiner ist, als normal. Verglichen mit der Distanz der Spinae anteriores superiores ist er um 115 Proc. kleiner gegen eine Differenz von 97,5 Proc. im normalen Becken.

3) Der quere Durchmesser des Ausganges ist kleiner als normal. Die Verengerung an dieser Stelle wäre eine hoch- 
gradige gewesen, wenn nicht der Symphysenspalt vorhanden wäre.

Aus 1) und 3) ergiebt sich ferner eine Vergrösserung des Winkels, den die beiden Hüftstachelsitzknorrenlinien mit einander bilden. Derselbe beträgt im normalen Becken $43^{\circ}$, in unserem $52^{\circ}$.

Fig. 10.

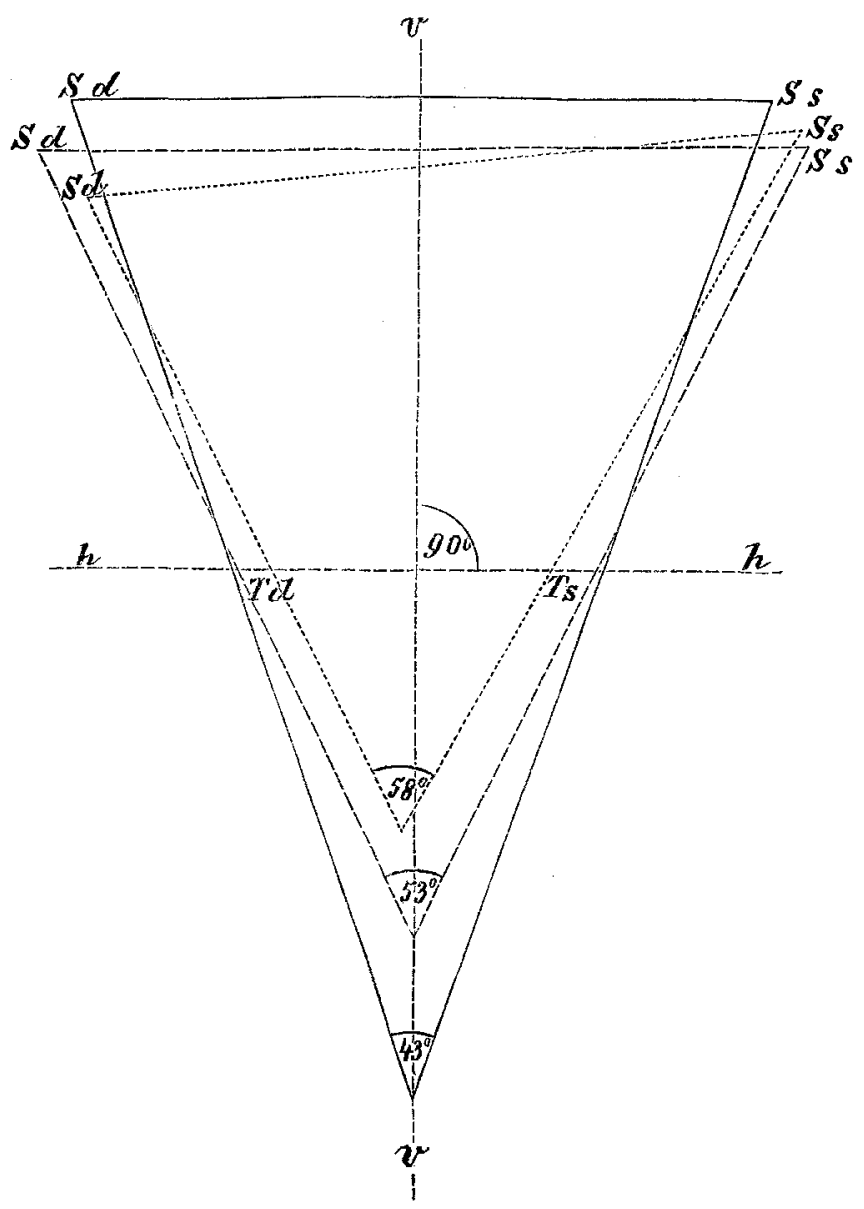

Bei der Construction der horizontalen Ebene ${ }^{1}$ ) tritt uns die Frage entgegen, welcher Punkt als Promontorium zu wählen

1) In die Fig. 11 ist ausserdem noch das nicht rachitisch kyphotische Becken (Breisky Nr. 15) mit punktirt gestrichelter linie zum Vergleich hineingezeichnet. 
ist. Nehmen wir bei unserem Becken $\mathrm{C}$ als solchen, wie normaler Weise, die Verbindungsstelle des ersten Kreuzbein- mit dem letzten Lendenwirbel, so zeigt die Vergleichung des Diagrammes mit dem des normalen Beckens, dass dieser Punkt $P$ weit hinter dem normalen liegt. Dadurch erhält der horizontale Durchschnitt unseres Beckens eine mehr rundliche Gestalt und nähert sich dem kypho-

Fig, 11.

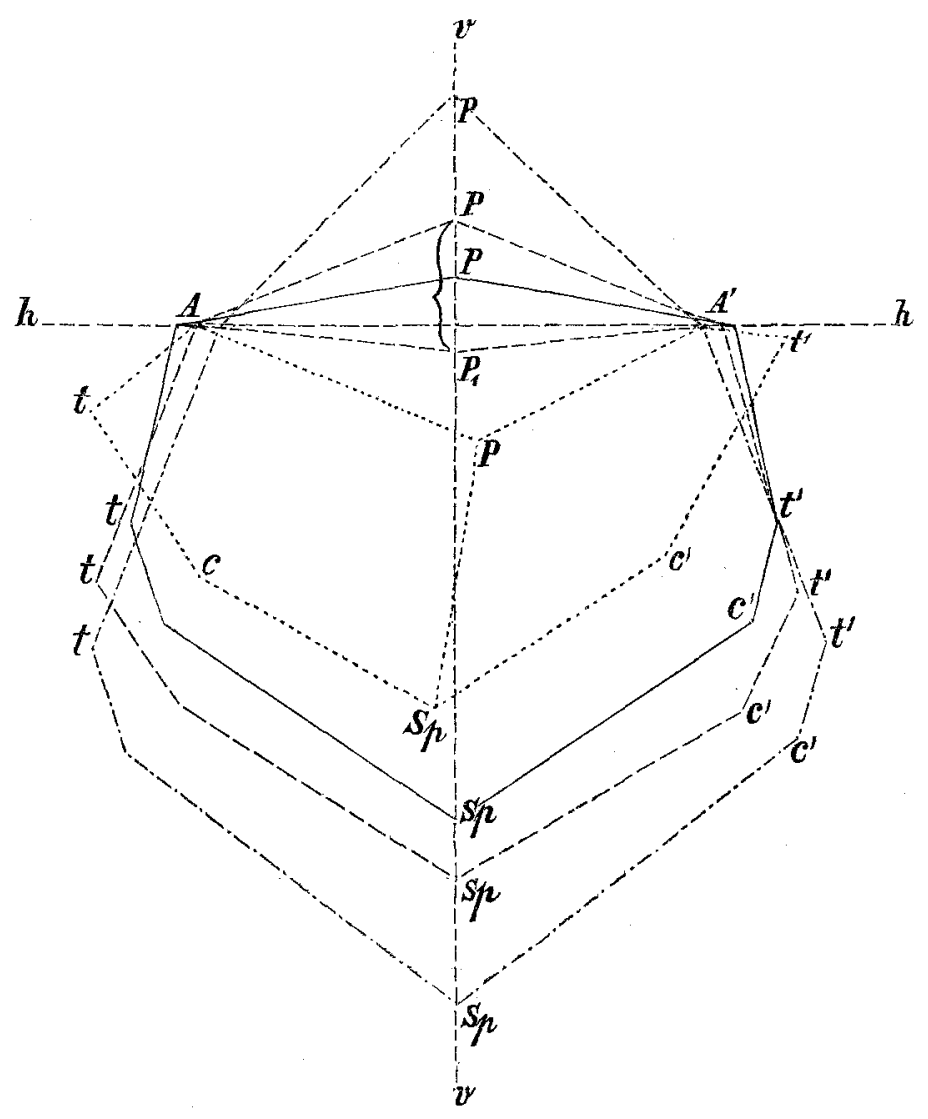

tischen Typus. Da jedoch, wie schon oben erwähnt, das eigentliche Promontorium hoch über der Linea terminalis liegt, so erscheint als der richtigere Maasspunkt zur Construction der Horizontalebene die Verbindungsstelle des ersten und zweiten Kreuzbeinwirbels, welcher mit den übrigen Maasspunkten in einer Ebene liegt und das geburtshülflich richtige Promontorium ist. Bei 
dieser Construction tritt die rachitische Form mehr zum Vorschein durch das Hervortreten der Kreuzbeinkörper vor den Flügeln und die dadurch bedingte Convexität des Sacrum der Quere nach, ohne dass jedoch dabei eine Abplattung von vorn nach hinten erreicht wird. Zeigt sich der Einfluss der Rachitis ferner noch darin, dass der quere Durchmesser den geraden des Einganges an Grösse übertrifft, so besteht andererseits eine Abweichung von der rachitischen Form darin, dass ersterer nicht dem Kreuzbein sehr nahe verläuft, sondern, wie beim rein kyphotischen Becken, sehr entfernt davon. Der vordere Querdurchmesser verläuft der Schamfuge näher als normal.

Hauptsächlich ersehen wir aus dieser Figur, sowie aus den absoluten und relativen Maassen:

1) Die Basis des Kreuzbeines ist verschmälert.

2) Die Conjugata vera des Beckeneinganges ist absolut und relativ vergrössert (cf. 'Sagittalebene).

3) Der grosse Querdurchmesser ist entsprechend dem rachitischen Typus relativ und absolut vergrössert und übertrifft die Conjugata vera.

4) Die schrägen Durchmesser sind vergrössert und von ziemlich gleicher Länge. Ueberhaupt theilt die Conjugata vera das Becken in zwei annähernd symmetrische Hälften.

Fassen wir zum Schluss das Gesammtresultat zusammen, so sieht man zur Genüge eine Bestätigung des von Breisky aufgestellten und von Le opold begründeten Satzes, dass nicht nur eine Kyphose, sondern anch eine Kyphoskoliose die rachitischen Eigenschaften eines Beckens wesentlich abzuschwächen, resp. denselben ganz entgegengesetzte Verhältnisse zu schaffen vermag. Die rachitischen Becken werden rund, selbst trichterförmig im Eingangerelativ erweitert, im Ausgangeverengt mit verminderter, doch noch deutlich vorhandener rachitischer Querspannung. Diese Abänderungen sind abhängig von dem Grade und dem Sitze der Wirbelabknickung. Im Becken B sind wegen des geringeren Grades und des hohen Sitzes der Kyphose die rachitischen Verhältnisse weniger modificirt, als im Becken C, wo die Kyphose eine sehr hochgradige und tiefersitzende ist. Daraus erklärt sich auch der verschiedene Geburtsverlauf in den beiden Fällen. Im Falle II konnte der Kopf die rachitische Verengerung, die durch die Kyphose abgeschwächt war, überwinden und fand auch am Beckenausgange kein Hinderniss, 
da die rachitische Erweiterung des geraden Durchmessers durch die Kyphose nicht abgeändert worden war. Die Geburt erfolgte daher spontan. Anders dagegen im Falle III (Becken C). Der kindliche Kopf konnte wegen der allgemeinen Erweiterung des Beckeneinganges leicht ins Becken eintreten und fand erst ein Hinderniss in dem verengten Beckenausgange, weswegen die Anlegung der Zange indicirt war.

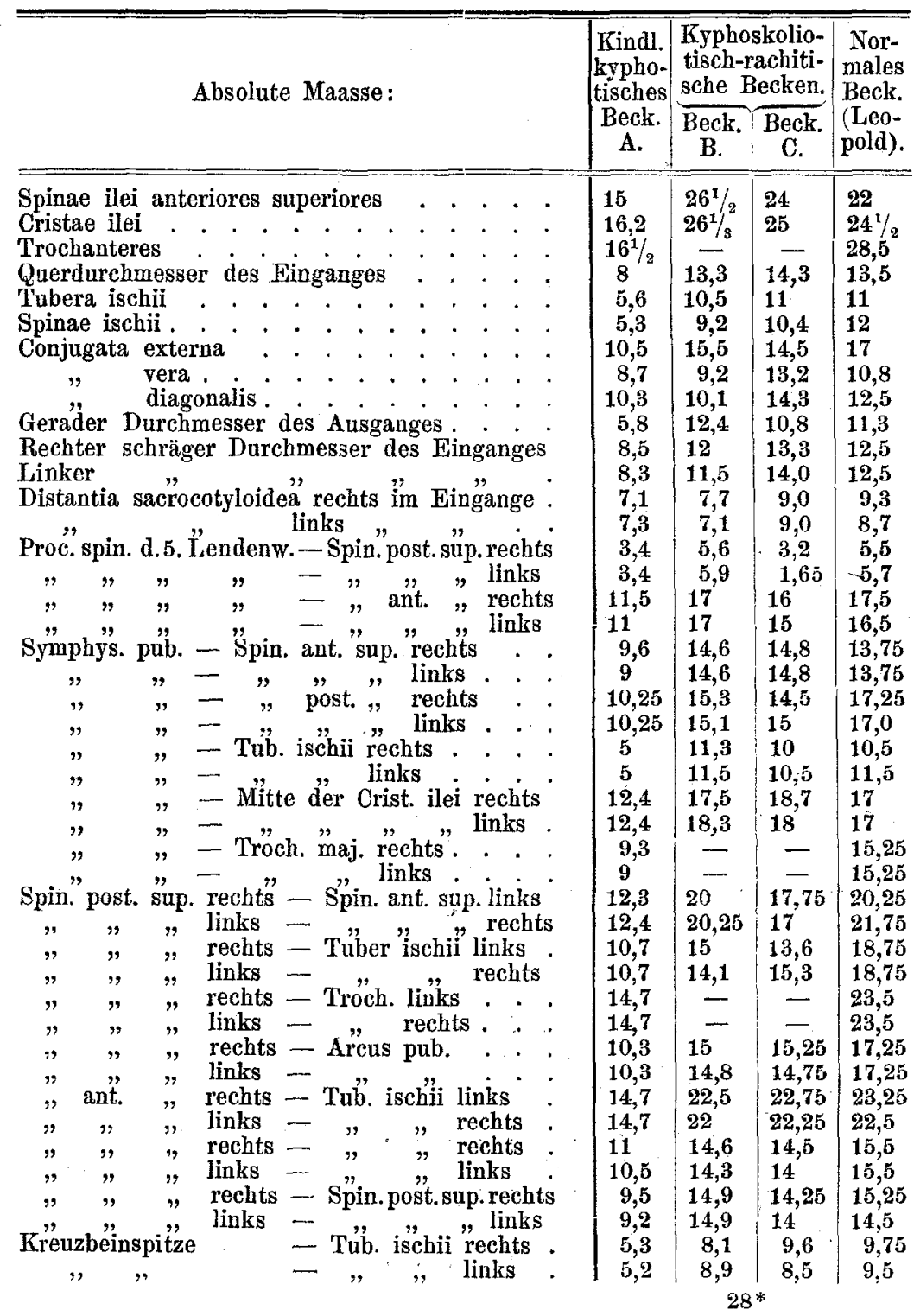


Sagittale Ebene.

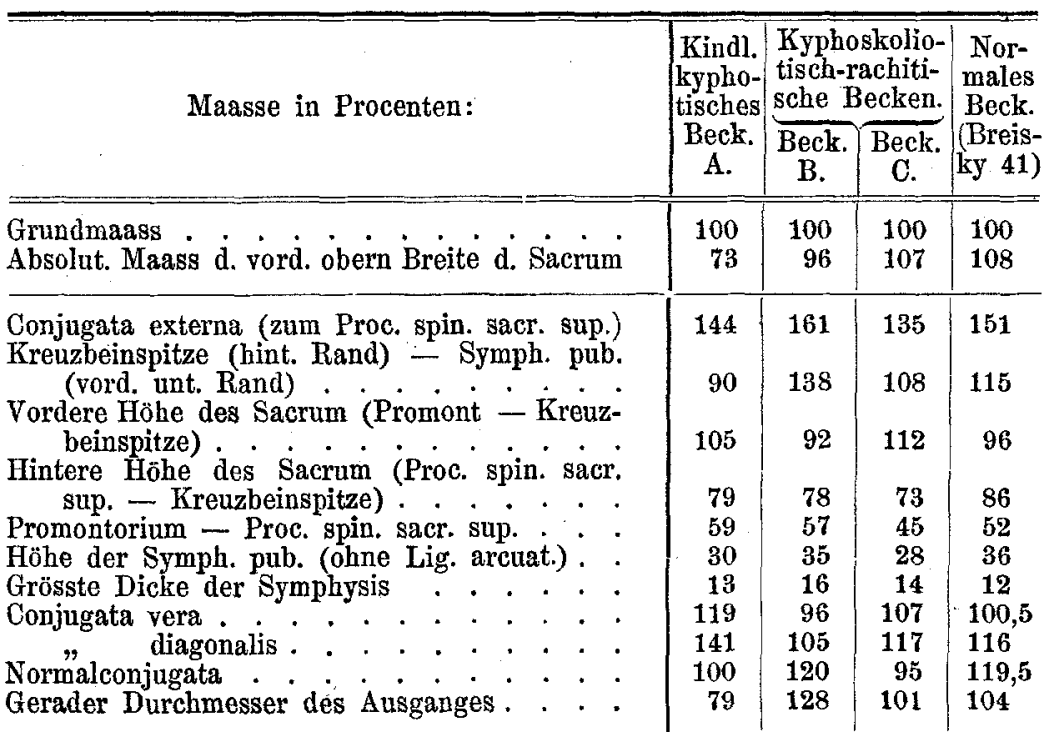

\section{Frontalebene.}

Spinae ilei anteriores superiores

Cristae ilei

Vorderer querer Durchmesser des Einganges.

Querer Durchmesser des Ausganges

Hüftstachelsitzknorrenlinie rechts

Spinae ilei posteriores "superiores

\begin{tabular}{r|r|r|l}
205 & 276 & $\mathbf{2 2 2}$ & 208 \\
222 & $\mathbf{2 7 4}$ & $\mathbf{2 3 4}$ & $\mathbf{2 4 8}$ \\
$\mathbf{9 0}$ & $\mathbf{1 1 8}$ & $\mathbf{1 0 7}$ & $\mathbf{1 1 0 , 5}$ \\
76 & $\mathbf{9 8}$ & 102 & $\mathbf{1 0 5 , 5}$ \\
$\mathbf{1 2 3}$ & $\mathbf{1 5 9}$ & $\mathbf{1 3 6}$ & $\mathbf{1 4 2}$ \\
$\mathbf{1 2 3}$ & $\mathbf{1 5 9}$ & $\mathbf{1 3 2}$ & $\mathbf{1 4 2}$ \\
61 & $\mathbf{7 5}$ & $\mathbf{4 4}$ & $\mathbf{7 1}$
\end{tabular}

\section{Horizontale Ebene.}

Spinae ilei anteriores superiore

Cristae ilei

\begin{tabular}{r|r|r|c}
205 & 276 & 222 & 208 \\
222 & 274 & 234 & 248 \\
61 & 75 & 44 & 71 \\
168 & 208 & 165 & 190 \\
170 & 210 & 159 & 190 \\
119 & 96 & 123 & 100,5 \\
109 & 138 & 133 & 119,5 \\
90 & 118 & 107 & 110,5 \\
116 & 125 & 126 & 117 \\
113 & 119 & 130 & 117 \\
97 & 80 & 84 & 82,5 \\
100 & 74 & 84 & 82,5 \\
96 & 122 & 93 & 115 \\
72 & 95 & 80 & 90 \\
71 & 99 & 70 & 90 \\
79 & 113 & 121 & 102 \\
79 & 88 & 85 & 83
\end{tabular}

Spin. ilei post. sup. rechts - Spin. ant. sup. links

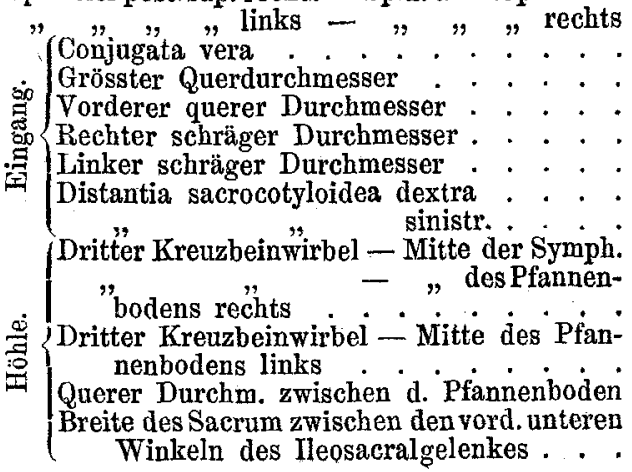




\begin{tabular}{|c|c|c|c|c|}
\hline \multirow[t]{2}{*}{ Maasse in Procenten: } & \multirow{2}{*}{$\begin{array}{c}\text { Kindl. } \\
\text { kypho- } \\
\text { tisches } \\
\text { Beck. } \\
\text { A. }\end{array}$} & \multicolumn{2}{|c|}{$\begin{array}{l}\text { Kyphoskolio- } \\
\text { tisch-rachiti- } \\
\text { sche Becken. }\end{array}$} & \multirow{2}{*}{$\begin{array}{l}\text { Nor- } \\
\text { males } \\
\text { Beck. } \\
\text { (Breis } \\
\text { ky 41) }\end{array}$} \\
\hline & & $\begin{array}{c}\text { Beck. } \\
\text { B }\end{array}$ & $\begin{array}{c}\text { Beck. } \\
\text { C. }\end{array}$ & \\
\hline 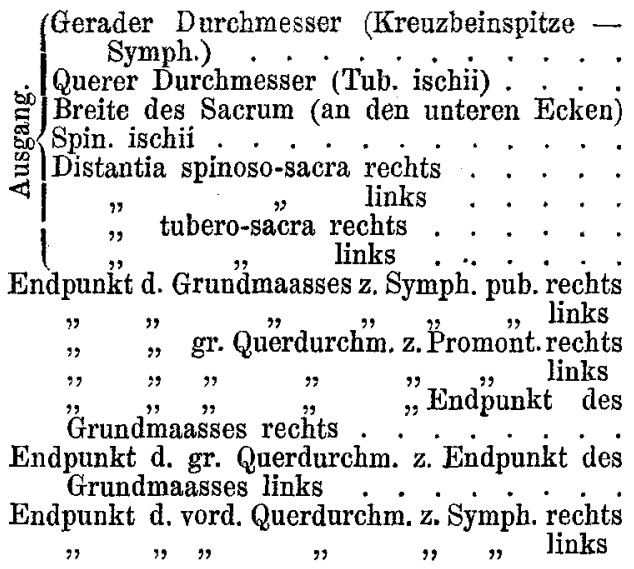 & $\begin{array}{r}79 \\
76 \\
59 \\
72 \\
27 \\
27 \\
68 \\
68 \\
116 \\
116 \\
126 \\
124\end{array}$ & $\begin{array}{r}128 \\
98 \\
52 \\
95 \\
64 \\
65 \\
88 \\
96 \\
111 \\
111 \\
73 \\
73\end{array}$ & $\begin{array}{r}101 \\
102 \\
54 \\
97 \\
44 \\
30 \\
80 \\
69 \\
113 \\
117 \\
83 \\
83\end{array}$ & $\begin{array}{c}104 \\
105,5 \\
51 \\
95 \\
41 \\
42 \\
60 \\
62 \\
108 \\
108 \\
73,5 \\
73,5\end{array}$ \\
\hline
\end{tabular}


\$
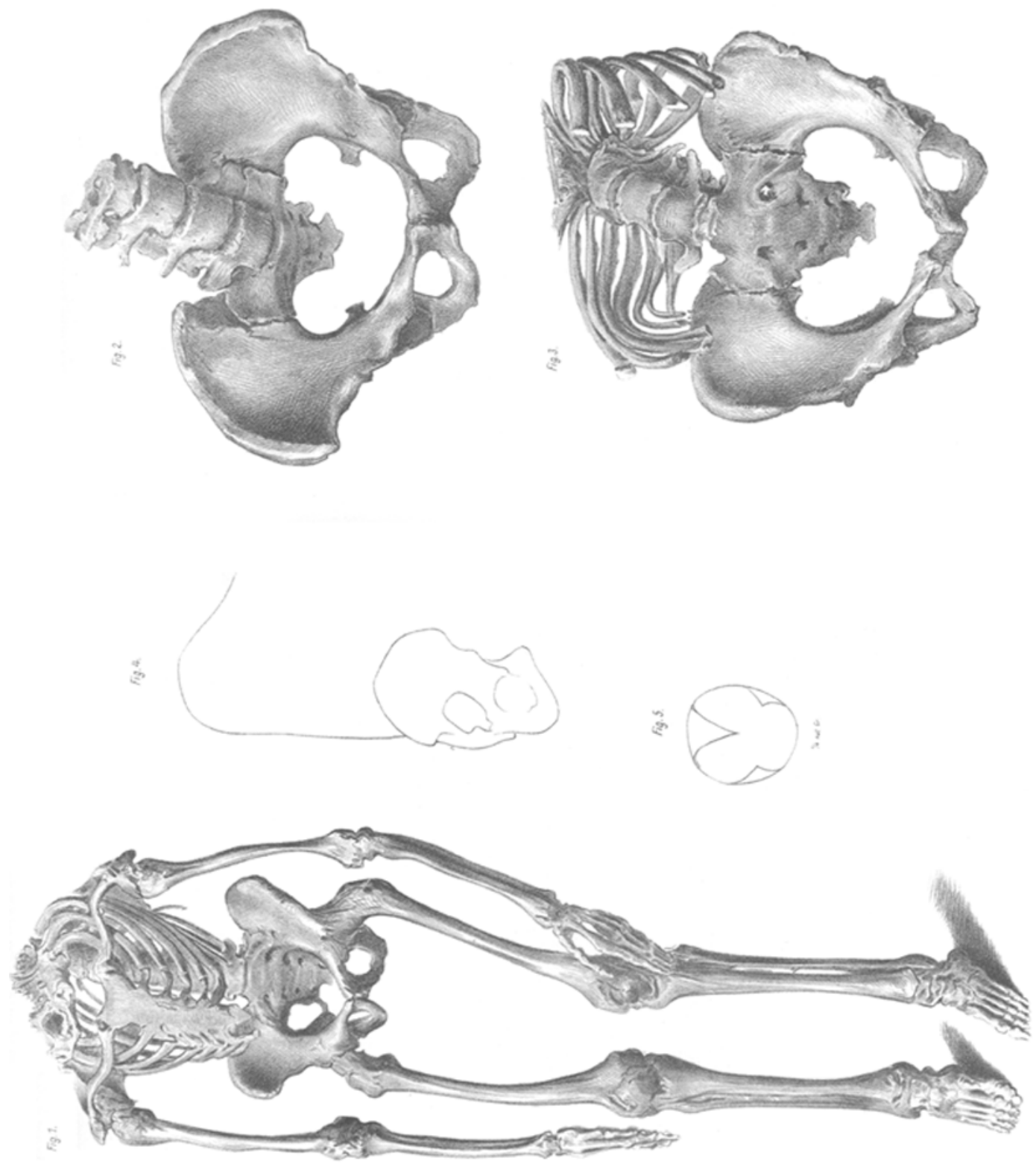

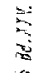

产 